\title{
EL MODELO VALENCIANO PARA LA GESTIÓN A TRAVÉS DE LA EXPERIENCIA APLICATIVA DE LA LRAU EN ALICANTE (1995-2005)
}

\section{Carles Gascó Verdier}

carlesgasco@ctav.es

Arquitecto,

Valencia, España

Remisión inicial: 18-9-2006 Remisión definitiva: 26-9-2006

\section{A Javier García-Bellido in memoriam}

Palabras Clave: modelo valenciano, Ley Urbanística Valenciana, LRAU

Resumen: La aprobación en 1994 de la Ley Reguladora de la Actividad Urbanística de la Comunidad Valenciana (LRAU) dio lugar al modelo valenciano para la gestión urbanística. Su aplicación a lo largo de más de una década ha puesto de manifiesto efectos en la producción de suelo urbanizado, derivados de la ruptura del monopolio en la gestión del suelo. El siguiente trabajo versa sobre el efecto de la competencia en la fase ejecutiva del planeamiento urbanístico.

El estudio realizado es de carácter empírico y se centra en la aplicación de la LRAU en la ejecución del Plan General de Ordenación de Alicante, aprobado en 1987. Los resultados indican que la aplicación del modelo valenciano de la LRAU comportó mejoras en la urbanización, especialmente en la materialización efectiva de las unidades de ejecución derivadas del planeamiento, a raíz de la potenciación de competencia latente. Sin embargo, el grado de competencia explícita en los concursos fue muy bajo y sólo se obtuvieron ligeros avances en las condiciones de producción de las actuaciones adjudicadas en régimen de competencia.

La reciente aprobación de la nueva Ley Urbanística Valenciana (LUV) asegura la continuidad del modelo valenciano de gestión urbanística, y supone una renovación de las reglas de juego.

\section{El modelo valenciano para la gestión urbanística}

La aplicación de la Ley 6/94 Reguladora de la Actividad Urbanística (LRAU) a lo largo de más de una década en la Comunidad Valenciana supuso un cambio radical en la gestión del urbanismo respecto al sistema tradicional español implantado con la ley del suelo de 1956, y sucesivas refundiciones. La LRAU, que no obtuvo en todo el tiempo de su vigencia su oportuno desarrollo reglamentario, fue derogada con la aprobación, en diciembre de 2005, de la nueva Ley 16/2005 Urbanística Valenciana (LUV). Este nuevo texto legal mantiene la competencia en la gestión urbanística, siendo ésta la línea maestra del que se ha denominado como Modelo Valenciano iniciado por la LRAU. El presente trabajo se ocupa en los efectos derivados de esta innovativa apuesta que introduce la libre competencia en la gestión y ejecución del planeamiento. 


\subsection{Razones y objetivos del modelo concurrencial valenciano.}

El principal objetivo de la LRAU consistió en desbloquear el proceso de creación de ciudad. De este modo, se abordaron las carencias estructurales del sistema urbanístico español para acometer la producción de suelo urbanizado mediante la ejecución planeamiento legalmente aprobado.

La lectura de la coyuntura anterior hecha por el legislador en 1994 puso de relieve una serie de problemas entre los que destacaban los largos plazos de ejecución del planeamiento (que rara vez cumplían la programación prevista) y la dificultad de sinergia entre la voluntad pública y la iniciativa privada. Estos problemas venían ocasionados por un sistema de aprobación y ejecución de los planes que era demasiado sofisticado para lograr "mejorar la calidad de vida ciudadana en términos compatibles con el fomento del desarrollo económico comunitario", propósito central de la acción urbanística según observaba el Preámbulo de la LRAU. Entre las causas de la inoperatividad del sistema se apuntaba fundamentalmente hacia la excesiva rigidez jerárquica del sistema de planeamiento y la tendencia a la burocratización, la inoperatividad de las Juntas de Compensación y, sobre todo, las dificultades de la propiedad del suelo para ejecutar las decisiones públicas en contraprestación al derecho a la plusvalía urbanística que se le asignaba por medio de la reclasificación. Las razones de esta incapacidad se encontraban, por un lado, en la habitual falta de coincidencia del propietario del suelo con el perfil de promotor-emprendedor $\mathrm{y}$, sobre todo, por el fracaso de la programación como instrumento de compatibilidad entre la acción pública y el interés privado (FERNÁNDEZ, 1993; BLANC, 1997).

Ante esta situación paralizante la LRAU desplegó una estrategia basada en una doble premisa: la apuesta renovadora consistió en enfatizar el carácter público de la función urbanizadora, al tiempo que se subrayó su reconocimiento como una típica actividad empresarial.

Desde estas posiciones se planteó una reforma del sistema que supuso, como principal novedad, una liberalización efectiva de la gestión del suelo, formulada en régimen de pública competencia, al potenciar la figura del agente urbanizador. De este modo, se reforzaron los mecanismos de gestión mediante una programación basada en los compromisos reales que fuese capaz de asumir el urbanizador integrando el riesgo de esta actividad emprendedora. Así, la programación dejó de ser resultado del acuerdo administrativo aplicado al terreno, pasando a depender de las garantías personales aportadas por el agente adjudicatario del Programa.

La otra gran reforma de la LRAU se dirigió hacia la agilización de los procedimientos, finalidad que se buscó a través de mayor flexibilidad en la definición y en la tramitación del planeamiento (BLANC, 1997). El presente trabajo centra su análisis en los modos de ejecutar el planeamiento sin contemplar, en aras del rigor metodológico, la oportunidad y las condiciones de formalización del mismo. Por lo tanto, en lo que concierne a nuestro estudio, la aprobación de la LRAU comportó, en definitiva, una revisión de los mecanismos de producción de ciudad al introducir la pública competencia en la actividad urbanizadora, que fue entendida explícitamente como una típica actividad empresarial. Veamos de qué modo. 


\subsection{Principios y bases de la gestión indirecta con la LRAU}

El objetivo de la tramitación de Programas a través de procesos concurrenciales es facilitar la puesta en el mercado de suelo urbanizado, dinamizando su producción y abaratando los costes del proceso.

¿Cuál es entonces el objeto de concurso sobre el que compiten los agentes, propietarios o no, en el marco del modelo urbanístico valenciano? Pues sencillamente aquello que ya venían realizando, en similar proporción, los propietarios y la Administración hasta la entrada en vigor de la LRAU. Es decir la urbanización, que es "la actividad material (y el resultado de la misma) de la mera y pura ejecución" de la decisión pública de transformación de suelo para la producción de nueva ciudad o mejora y renovación de la existente (PAREJO, 2002).

Este cambio en la práctica gestora del planeamiento no supuso en ningún caso una alteración de las "condiciones básicas de igualdad en el ejercicio del derecho de propiedad" (VAQUER, 2002) sino una apertura del, hasta entonces, limitado elenco de actores que podían acceder a realizar la acción de transformar el bien 'suelo' para producir ciudad, de conformidad con las determinaciones fijadas en el planeamiento.

El derecho de la propiedad quedaba entonces inalterado dado que la legislación autonómica no podía incidir en el régimen urbanístico al tratarse de una competencia estatal. Manteniendo el principio básico español de equidistribución de beneficios y cargas, el legislador valenciano incidió (explorando la vía abierta por la ley estatal de 1975) en la diferenciación entre el estricto contenido de la propiedad urbanística y la propia acción urbanizadora.

Veamos someramente cuál es, en el modelo valenciano, el papel de los distintos agentes participantes en el proceso:

- El poder público municipal conserva y consolida su posición de control y dirección del desarrollo urbano. Compete al Ayuntamiento-Pleno la aprobación en pública competencia de una alternativa técnica (una ordenación detallada y las calidades de su obra) y la adjudicación de su urbanización al particular que presente la proposición jurídico-económica más competitiva (plazos, garantías, coste de las obras y beneficio empresarial).

- El agente designado como urbanizador (público o privado, propietario o no) asume el compromiso de gestionar la operación que concluirá con la transformación urbanística del suelo, ejecutando la misma en los plazos y condiciones fijadas en el Programa. Debe asumir los costes de urbanización y la financiación de la operación, y recibe una compensación a cambio por parte de los propietarios que podrá ser económica 0 mediante la parte equivalente de terrenos urbanizados.

- La posición de los propietarios de suelo urbanizable se reduce a dos supuestos: a) transformarse voluntariamente en agentes urbanizadores $o b$ ) incorporarse al proceso a remolque de un tercero, ya sea propietario o no de terrenos, mediante una colaboración pactada con el urbanizador por la que recibirán parcelas edificables. La participación de los propietarios en el proceso se fomenta a través de un régimen de adjudicación preferente, primándose el mayor grado de consenso posible.

\subsection{Resultados aplicativos y valoraciones globales}


Los efectos generados por el cambio de sistema fueron inmediatos. Desde la implantación de la LRAU, la actividad urbanizadora en la Comunidad Valenciana ha mantenido un fuerte dinamismo caracterizado por el incremento de la inversión privada en urbanización. También se ha podido confirmar el uso extensivo de los nuevos instrumentos, siendo homogénea su aceptación en todo el ámbito territorial de aplicación de la LRAU (GAJA, 2000; MODREGO, 2000).

Los datos oficiales sobre la actividad urbanística en la Comunidad Valenciana fueron describiendo la descongestión que se produjo desde la entrada en vigor de la LRAU. En un principio, este despegue espectacular de la inversión en obra urbanizadora se llegó a describir como un verdadero "consenso urbanístico valenciano" (MODREGO, 1997). Sin embargo, este entusiasmo inicial fue seguido de un ambiente de controversia entorno a la Ley tras unos años de experiencia aplicativa. Ello supuso que surgieran líneas críticas en respuesta a determinados fenómenos cuyo origen se identificó con la LRAU. Las posiciones contrarias a la Ley se resumen en un planteamiento doble que engloba, por un lado, a la posición de una parte de la propiedad del suelo frente a los abusos a los que, según denuncian, se ven sometidos como resultado del proceso de adjudicación de Programas. Por otro lado, existe la línea crítica que apunta hacia la LRAU (entre otros factores) como causa de un desarrollo ineficaz en términos ambientales y poco sostenible social y económicamente, dadas las repercusiones territoriales que serían resultado de su aplicación (GAJA, 2000; MONTIEL, 2003). Estas críticas al fundamento del nuevo sistema obtienen respuesta en las posiciones que, aún reconociendo que el texto adolecía de algunos problemas instrumentales, atribuyen dichas deficiencias sobre todo a problemas aplicativos (FERNÁNDEZ, 2005).

Desde el punto de vista científico, se constata la dificultad que existe para aprovechar la experiencia en el caso de la fábrica urbana, especialmente cuando ésta se ve envuelta por la polémica. Se trata de un sistema productivo donde la toma de decisiones no suele realizarse conociendo, analizando y evaluando la experiencia de lo realizado anteriormente en términos cuantitativos y cualitativos. En este hueco pretende insertarse este trabajo, con la voluntad de contribuir a la racionalización de las pautas de intervención en la fabricación, transformación y renovación de la materia que sirve de soporte a la mayoría de las actividades humanas: el espacio urbanizado.

\section{Planteamiento de la investigación}

El presente estudio plantea, en clave empírica, un análisis de los resultados de la gestión del planeamiento derivado del Plan General de Alicante (1987) mediante la aplicación de las reglas de juego de la LRAU. Aspiramos a conocer los hipotéticos efectos que, en términos de la competencia, comportó la ruptura del monopolio en la gestión urbanística a lo largo de una década de aplicación del nuevo modelo concurrencial.

Terminología en nuestro análisis de la competencia en el marco del modelo valenciano de la LRAU distinguimos dos categorías: la competencia explícita y la competencia latente o implícita.

Al referirnos a la competencia explícita designaremos aquella que se produce efectivamente cuando, en la pugna por la adjudicación de un Programa y por la consecuente obtención de la condición de agente urbanizador, surgen dos o más proposiciones formuladas por agentes diferenciados y de intereses contrapuestos, en los plazos y condiciones establecidas 
legalmente para la presentación de ofertas. Es la competencia "directa" entre plicas pugnando en un mismo concurso.

Por otro lado, al hablar de competencia latente nos referiremos a la amenaza potencial, es decir, a la mera posibilidad de que, al acometer un proceso de adjudicación de Programa, surjan diversas propuestas distintas optando a ser seleccionadas. Esta circunstancia surge con la posibilidad, favorecida en el modelo de la LRAU, de que existan iniciativas distintas a las de la propiedad para llevar a cabo la ejecución del planeamiento. Esta categoría significa, para el candidato dispuesto a presentar una alternativa de programa, que existe una presencia hipotética de otras alternativas que pretendan pujar por la adjudicación de una misma actuación determinada.

Aclaración sobre la polisemia de la palabra competencia: al emplear este término nos referimos a la contrastación o conflicto de intereses de dos o más partes sobre la misma cosa o materia que pugnan $u$ ofertan por hacerla suya. Empleamos competencia en este sentido, el de la concurrencia, en vez del que designa a la materia o actividad o práctica que pertenece en exclusiva (derivada o compartida) a una sola persona o ente en el ejercicio de sus funciones, diferenciándose en ello de otras análogas para ese ejercicio funcional.

\section{Problema metodológico}

La evaluación de la eficacia de un sistema de gestión urbanística implica, ante todo, un problema metodológico al tratarse de un fenómeno complejo que engloba una multitud de variables. El propósito de dotar de rigor a nuestro análisis nos sitúa ante la imposibilidad de aislar variables para analizar sus efectos por separado. Ante esta dificultad, nuestro planteamiento consistió en recorrer la casuística del total de las unidades de ejecución desarrolladas, incluyendo por tanto la globalidad de las circunstancias que acompañaron a la ejecución del planeamiento. De este modo obtuvimos una colección de muestras que, pese a la imbricación entre variables, permite llevar a cabo un estudio de tendencias dado que se trata de una muestra finita, correspondiente a las múltiples situaciones a que dio lugar la ejecución del Plan General en el marco de la LRAU.

El trabajo consta de dos partes, que se corresponden con dos preguntas genéricas o cuestiones mediante las cuales pretendemos analizar los hipotéticos efectos generados por la competencia en la ejecución del planeamiento en Alicante. En primer lugar analizamos a través de la cuestión primera los efectos cuantitativos derivados de la existencia de la competencia latente, respecto a la situación previa a la LRAU. Es decir, investigamos la incidencia que pueda haber generado la LRAU en el volumen de urbanización gestionado en el marco del planeamiento alicantino, comparando la proporción de viviendas en ámbitos gestionados por medio de la LRAU, respecto al mismo dato referido a actuaciones gestionadas mediante instrumentos de la ley del suelo de 1976.

La cuestión segunda consiste en una evaluación de los hipotéticos resultados cualitativos (medidos en términos de tiempo y costes) obtenidos como consecuencia del grado de competencia explícita existente durante la fase de adjudicación de Programas, en el marco de los procesos concurrenciales de la LRAU. Ante la dificultad de encontrar relaciones causales evidentes acudimos, como propone Muñoz (2005), a las técnicas desarrolladas por las ciencias sociales para abordar problemas experimentales planteando una relación entre dos preguntas 
generales, que procuramos resolver a través de tres preguntas especificas. En primer lugar, ¿qué grado de competencia explícita existió en los concursos de aprobación y adjudicación de Programas? Después, ¿qué resultados globales se derivan de la gestión integrada de actuaciones mediante instrumentos de la LRAU? Y finalmente con la tercera pregunta se examinarán las relaciones causales que podemos establecer a raíz de las respuestas anteriores. Es decir, ¿en qué medida llega a influir la presencia o no de competencia en los resultados de ejecución del planeamiento?

Figura $N^{\circ}$ 1: Análisis de los resultados de la gestión en términos de la competencia explícita.

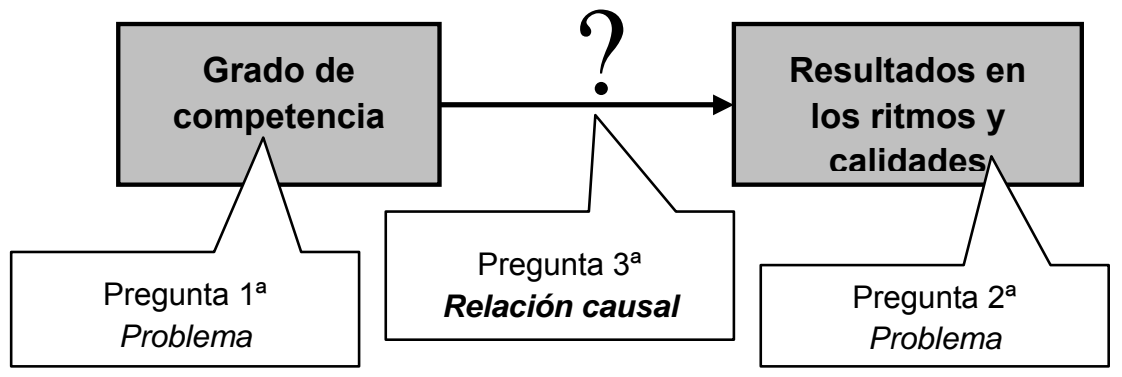

\section{Elaboración propia}

\section{Resultados del estudio en el municipio de Alicante.}

\subsection{Primera cuestión. Efectos de la competencia latente en los niveles de producción de suelo urbanizado.}

En nuestro estudio empírico, hemos establecido el punto de partida tratando de conocer si existieron diferencias significativas en la cantidad de suelo gestionado desde la aprobación del Plan General hasta la entrada en vigor de la LRAU, y entre el periodo de aplicación del modelo valenciano, hasta el año 2005. Analizaremos por tanto las incidencias en términos cuantitativos.

Para resolver esta cuestión obtuvimos los datos correspondientes al número de viviendas resultantes de todas las actuaciones ejecutadas, mediante la consulta de los documentos de planeamiento o de reparcelación con aprobación provisional o definitiva por parte del Ayuntamiento. Se extrajeron así los datos sobre la totalidad de las operaciones derivadas del Plan General de Alicante en las que la transformación de suelo se hubiese realizado a través de actuaciones integradas, entre 1988 y 2004. En los casos tramitados conforme a la Ley del Suelo estatal de 1976, la programación efectiva se llevó a cabo a través del sistema de compensación o, en menor número de casos, por cooperación. Con la LRAU la ejecución de los planes se realizó mediante Programas de Actuación Integrada, ya fuese mediante gestión pública (directa) o privada (indirecta).

Partiendo de las previsiones de crecimiento establecidas en la Memoria del Plan General de Alicante se alcanza un potencial edificatorio de vivienda nueva de 51.709 unidades. En esta cantidad se incluyen 7.772 viviendas en suelo urbano (SU) correspondientes a Unidades de Actuación (UA) y Áreas de Planeamiento Diferido (APD), a ordenar mediante planes de reforma interior y 20.687 viviendas en suelo urbanizable programado (SUP) a desarrollar por medio de 
Planes Especiales/Áreas de Planeamiento Anterior (PE/APA) y de Planes Parciales (PP). Por otro lado, la previsión hecha por el Plan General daba lugar a una capacidad adicional de 28.459 viviendas a desarrollar por medio de Programas de Actuación Urbanística (PAU) en suelo clasificado como urbanizable no programado (SUNP). De acuerdo con lo establecido por el sistema de gestión de la LS'76, los sectores del PG de Alicante correspondientes al primer y segundo cuatrienio debían, encontrarse en fase de ejecución con un compromiso real en el momento de entrada en vigor de la LRAU.

Al observar las áreas ejecutadas, o en fase de ejecución (con programación comprometida) se obtuvieron los siguientes datos, diferenciando si la gestión corresponde a instrumentos propios de la ley estatal o a los novedosos de la LRAU:

Figura $\mathbf{N}^{\circ}$ 2: Número de viviendas resultantes de actuaciones integradas

\begin{tabular}{|c|c|c|c|c|}
\hline \multirow[b]{2}{*}{ SU y SUP } & \multirow{2}{*}{$\begin{array}{c}\text { PREVISIÓN } \\
\text { PG } 1987\end{array}$} & \multicolumn{3}{|c|}{$\begin{array}{l}N^{\circ} \text { viviendas en actuaciones } \\
\text { ejecutadas o en tramitación }\end{array}$} \\
\hline & & LS '76 & LRAU '94 & Total \\
\hline UA & 3.402 & 1.753 & 911 & 2.664 \\
\hline APD & 4.370 & 1.917 & 1.346 & 3.263 \\
\hline PE/APA & 8.997 & 3.732 & 4.161 & 7.893 \\
\hline PP & 11.690 & 3.205 & 8.386 & 11.592 \\
\hline \multirow[t]{2}{*}{ Total SUP } & 28.459 & 10.607 & 14.805 & 25.412 \\
\hline & & $42 \%$ & $58 \%$ & $100 \%$ \\
\hline SUNP & PG 1987 & LS '76 & LRAU '94 & Total \\
\hline \multirow[t]{2}{*}{ PAU } & 23.250 & 1.422 & 15.477 & 16.899 \\
\hline & & $8 \%$ & $92 \%$ & $100 \%$ \\
\hline SUP+SUNP & PG 1987 & LS '76 & LRAU '94 & Total \\
\hline \multirow[t]{2}{*}{ Total } & 51.709 & 12.029 & 30.282 & 42.311 \\
\hline & & $28 \%$ & $72 \%$ & $100 \%$ \\
\hline
\end{tabular}

Fuente: Elaboración propia

A partir de estos resultados podemos extraer las siguientes conclusiones acerca de la eficacia de la gestión urbanística a través de mecanismos propios de las leyes estatal de 1976 y valenciana de 1994:

- La programación establecida desde el Plan General para los dos cuatrienios sólo fue ejecutada en un $50 \%$ mediante los mecanismos propios de la ley estatal, lo que suponía un retraso respecto a sus previsiones.

- La producción de suelo urbanizado aumenta de modo palpable desde el momento de la ruptura del monopolio de la gestión urbanística y la consiguiente aparición de competencia latente. A través de los procedimientos favorecidos por la LRAU se consigue programar todo el suelo que quedaba pendiente de ejecución, heredado de la situación anterior.

- Además, el nuevo instrumento facilita una respuesta muy eficaz a la demanda puesto que se consigue comprometer un $66 \%$ del suelo urbanizable no programado, que 
formaba parte del colchón de holgura dispuesto por el planificador para atender a una eventual demanda sobrevenida.

A la vista de estos resultados se concluye que el cambio de modelo efectuado con la aprobación de la LRAU, supuso una evidente influencia en la ejecución del planeamiento. Los cambios introducidos dieron lugar a un aumento del volumen de suelo gestionado desde la entrada en vigor de la ley. Este hecho, referido en nuestro caso al municipio de Alicante, coincide con la tendencia experimentada en el resto del territorio valenciano como viene recogido en los trabajos de BLANC (1997) y GAJA (2000).

\section{Figura № 3: Número de actuaciones urbanísticas anuales en la Comunidad Valenciana}

\begin{tabular}{|l|l|l|l|}
\cline { 2 - 4 } \multicolumn{1}{c|}{} & $1990-1994$ & $1994-1996$ & $1994-1998$ \\
\hline $\mathrm{N}^{\circ}$ actuaciones & - & 245 & 736 \\
\hline Tramitadas / año & 40 & 136 & 184 \\
\hline Aprobadas / año & 40 & $80-100$ & 496 \\
\hline
\end{tabular}

Fuente: Generalitat Valenciana a través de BLANC (1997) y GAJA (2000).

Elaboración propia

\subsection{Segunda cuestión. Incidencias en los resultados de la gestión derivadas de la competencia explícita.}

Una vez analizados los resultados cuantitativos, procedemos a estudiar en la siguiente cuestión los efectos de la competencia explícita en los resultados de la gestión del Plan. Se trata por tanto de descifrar las condiciones en las que, caso de existir, se produjo la competencia para, a su vez, extraer los efectos cualitativos que pudieran derivarse de la adjudicación de Programas entre plicas presentadas por agentes compitiendo libremente por obtener la condición de urbanizador.

3.2.a Grado de competencia explícita

La toma de datos se realizó a partir de una población finita, correspondiente a la totalidad de PAls aprobados y adjudicados en Alicante durante el período comprendido entre la entrada en vigor de la LRAU hasta septiembre de 2005 (10 años). La tramitación de estos Programas supuso la apertura de 56 expedientes administrativos que comportan la evaluación, aprobación y desarrollo de los respectivos instrumentos de planeamiento y de gestión. Estos expedientes son las unidades muestrales de nuestro estudio. Antes de desmenuzar la casuística de los concursos, repasaremos someramente las reglas de juego de los mismos con la LRAU.

El procedimiento concursal en la LRAU.

La apertura del proceso urbanizador a iniciativa de un particular se produce al proponer éste al alcalde (caso general) o ante notario (caso simplificado) una oferta elaborada mediante un Programa, y finaliza con su adjudicación a un urbanizador en concurso público. Una vez estimada la propuesta se abre una fase de información pública en la que se recogen las posibles alegaciones o, en su caso, otras proposiciones económico-financieras presentadas por otros candidatos. La alternativa técnica del Programa admitido a tramitación se convierte en la base, a modo de pliego de condiciones, para la elección del agente urbanizador. Se trata de una base sólo orientativa, puesto que queda abierta la posibilidad para que se presenten otras variantes o alternativas técnicas. El plazo para la presentación de otras alternativas técnicas es de veinte días, prorrogables por veinte días adicionales al existir un compromiso real por parte alguna persona de presentar otra alternativa técnica sustancialmente distinta a la original. Todo 
ello sitúa el plazo máximo para la recepción de alternativas en competencia en cuarenta días, desde la fecha de la convocatoria de la información pública.

La elección del urbanizador se hace a través del concurso público, dándose preferencia a las propuestas que cuenten con el acuerdo de los propietarios mayoritarios. Con la aprobación del PAl por el ayuntamiento-pleno se definen las obligaciones y compromisos entre los distintos agentes, existiendo un plazo máximo (5 años) para ejecutar las obras. La aprobación del Programa de Actuación Integrada requiere por tanto la previa selección de la alternativa técnica que más se ajuste a los requisitos municipales. Sobre dichos requisitos técnicos se producirá la verdadera competencia entre plicas dado que, como consecuencia de la aprobación de una alternativa técnica por parte del municipio, sólo serán susceptibles de ser elegidas aquellas proposiciones jurídico-económicas que se hubiesen formulado para el desarrollo de aquella. La aprobación del Programa va ligada a su adjudicación al agente que presenta la proposición jurídico-económica más competitiva de acuerdo con los criterios establecidos legalmente y con aquellos suplementarios que, por anticipado, haya podido determinar la administración local.

Muestreo Para completar el estudio del grado de competencia diferenciamos tres campos de concurrencia: totalidad de alternativas técnicas presentadas (AT), totalidad de proposiciones jurídico-económicas presentadas (PJ-E), sin distinguir qué alternativa técnica aspiraba a ejecutar cada agente y, por último, la selección de (únicamente) aquellas proposiciones jurídico-económicas que fueron formuladas para ejecutar la alternativa técnica que resultó efectivamente aprobada (PAI). Designaremos los tres grupos anteriores mediante las siglas AT, $P$ J-E y PAI, respectivamente.

De estos tres niveles sólo puede existir competencia en sentido estricto (sometidas al acuerdo municipal) en el primer campo (entre AT) y en el último (PJ-E presentadas a la AT escogida). Es decir, la competencia explícita se produce en los dos concursos en los que, con carácter cronológicamente sucesivo, se aprueba la AT y se adjudica el Programa a quién presentó la mejor PJ-E de las formuladas a la AT escogida. Aunque el resto de PJ-E, formuladas para optar a la gestión de AT distintas a la finalmente escogida, no participan explícitamente en el concurso para la adjudicación del Programa (al quedar descartadas) hemos optado por recoger este dato por ser un buen indicador del grado de participación de la iniciativa privada en los concursos.

De los 56 expedientes que conforman los ámbitos gestionados por medio de Programas de Actuación Integrada en Alicante, hemos extraído la información relativa al grado de competencia explícita sobre 48 actuaciones. Las actuaciones que no forman parte de nuestro estudio son, en primer lugar, 5 unidades de ejecución cuyos correspondientes expedientes administrativos están incompletos al tratarse de operaciones iniciadas con anterioridad a la entrada en vigor de la LRAU y/o adaptadas a la ley en la fase inicial de la misma. Tampoco hemos incluido en el estudio 3 actuaciones que se encontraban, en el momento de la toma de datos, en una fase muy joven de tramitación. En todo caso podemos afirmar que las 48 actuaciones son una muestra significativa puesto que abarcan más de un $85 \%$ de la totalidad de casos y porque se incluyen todas las operaciones de mayor tamaño (en suelo urbanizable) donde se dan las condiciones de mayor atractivo para el mercado inmobiliario.

Los datos de esta sección se obtuvieron por medio de la consulta de las actas municipales de acuerdos plenarios de aprobación y adjudicación de Programas. Su estudio ha permitido conocer el número y la titularidad de las plicas presentadas, así como la identificación de las que resultaron finalmente elegidas por la mayoría del pleno municipal. 
Figura $\mathrm{N}^{\circ}$ 4. Alicante: localización de actuaciones tramitadas mediante PAls (1995-2005)

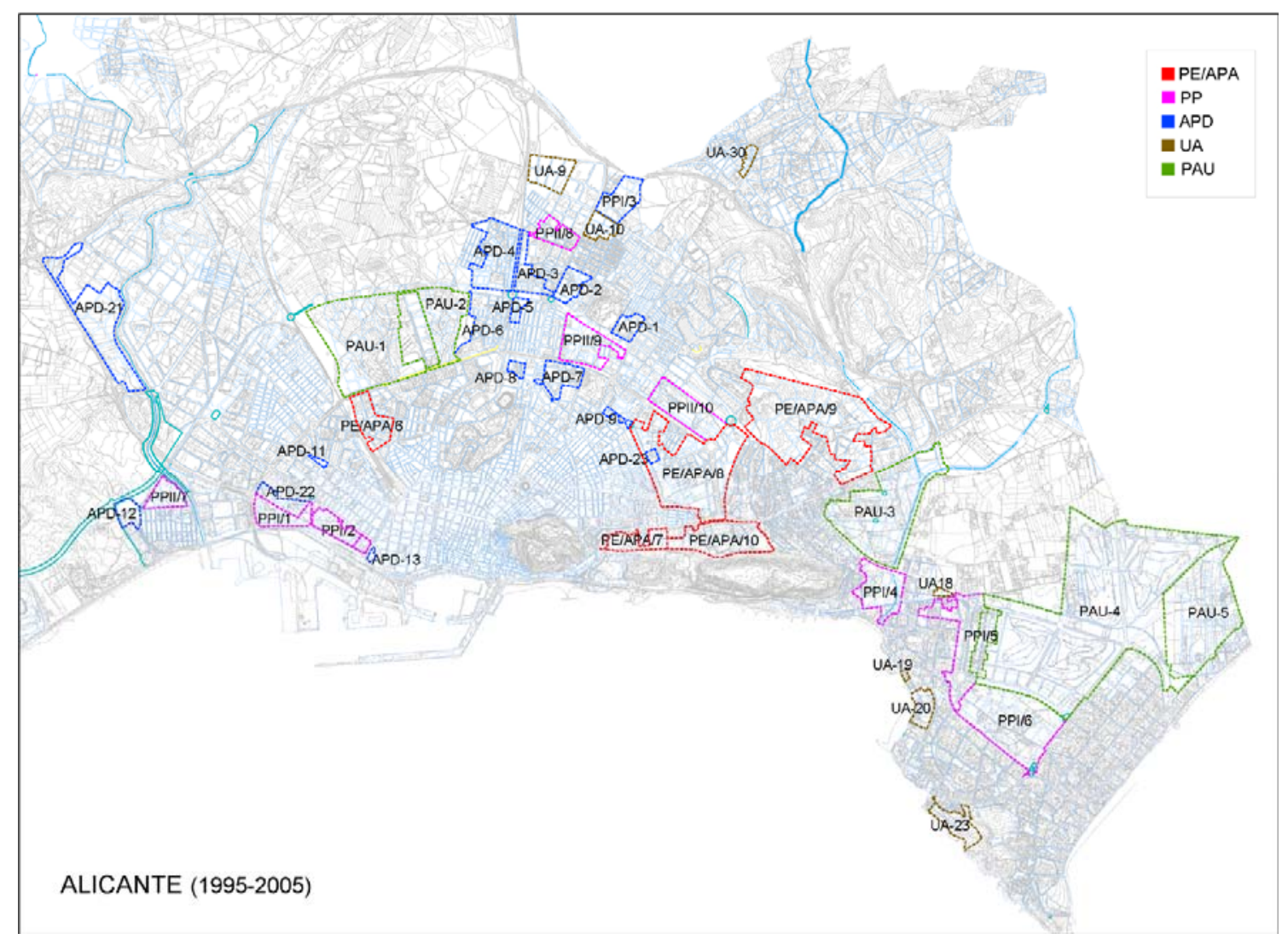

Fuente: Elaboración propia con asistencia de Basilio Moreno en la parte gráfica.

\section{Resultados y discusión}

Esta abundante recopilación de datos nos ha permitido conocer cuál fue el grado de competencia explícita en los procesos de adjudicación de PAls, a lo largo de los diez primeros años de aplicación de la LRAU en el municipio de Alicante. Los resultados, mostrados de forma sintética en la FIG. 5, expresan el grado de competencia atendiendo al número de actuaciones donde se presentaron como mínimo dos candidaturas distintas optando por obtener la condición de agente urbanizador. Estas candidaturas pudieron formularse mediante un Programa completo (AT y PJ-E) o presentando únicamente una PJ-E, licitando por una de las alternativas técnicas presentadas por otros candidatos. 
Figura $N^{\circ}$ 5: Actuaciones con gestión indirecta y grado de competencia explícita

\begin{tabular}{lcccccc} 
& \multicolumn{2}{c}{ S. urbano } & \multicolumn{2}{c}{ S. urbanizable } & \multicolumn{2}{c}{ Total municipio } \\
\hline Total actuaciones & 21 & $100 \%$ & 24 & $100 \%$ & 45 & $100 \%$ \\
\hline Competencia AT & 3 & $14,3 \%$ & 11 & $45,8 \%$ & 14 & $31,1 \%$ \\
Competencia P J-E & 5 & $23,8 \%$ & 11 & $45,8 \%$ & 16 & $35,6 \%$ \\
Competencia PAI $^{*}$ & 3 & $14,3 \%$ & 2 & $8,3 \%$ & 5 & $11,1 \%$
\end{tabular}

* Proposiciones jurídico-económicas que se formularon para ejecutar las alternativas técnicas que resultaron finalmente aprobadas. Fuente: Elaboración propia

Los resultados ponen de manifiesto la escasa competencia explícita, es decir, entre candidaturas distintas pujando por ejecutar un mismo ámbito. Tan sólo en un $31,1 \%$ de los casos a nivel de todo el municipio se presentaron al menos dos o más AT, subiendo ligeramente hasta $36,6 \%$ en el caso de las PJ-E que, recordémoslo, fueron formuladas sin conocer de antemano la AT que resultaría aprobada. La escasez de competencia resulta evidente cuando analizamos la relación de actuaciones en las que se hubiesen presentado más de una Proposición tendente a ejecutar la AT que resultó elegida efectivamente por el Ayuntamiento. En estos supuestos, que a fin de cuentas constituyen el verdadero concurso de gestión una vez conocida la ordenación, las adjudicaciones en competencia tan solo se situaron entorno al $10 \%$ del total (48) de las actuaciones analizadas.

Por otro lado, estos resultados coinciden en buena medida con las cifras que se desprenden del análisis de la competencia en función del tamaño (en términos de edificabilidad) de las actuaciones programadas (FIG. 6). Obtenemos este indicador sumando la edificabilidad que se desprende de todas aquellas actuaciones donde, para optar a la ejecución del Programa, fuesen presentadas en el concurso más de una AT, o de una P J-E.

Figura $\mathbf{N}^{\circ}$ 6: Grado de competencia expresado en términos de edificabilidad acumulada

\begin{tabular}{|c|c|}
\hline Programas & Edificabilidad \\
\hline Total en ejecución & $4.578 .785 \mathrm{~m}^{2} \mathrm{t}$ \\
\hline Competencia en AT & $1.744 .151 \mathrm{~m}^{2} \mathrm{t}$ \\
\hline Competencia en P.J-E & $1.772 .927 \mathrm{~m}^{2} \mathrm{t}$ \\
\hline Competencia en PAI & $424.118 \mathrm{~m}^{2} \mathrm{t}$ \\
\hline
\end{tabular}

En cualquier caso, se comprueba que, en términos generales, la proporción de plicas presentadas en competencia por la AT y la PJ-E es mayor en las unidades de ejecución en el suelo urbanizable. Sin embargo, esta tendencia se invierte al analizar la competencia real entre plicas (PAl) al producirse en un $8,3 \%$ de los casos en suelo urbanizable frente al $14,3 \%$ del suelo urbano. Señalemos que la clasificación del suelo tan sólo supone, a raíz del nuevo concepto clasificatorio introducido por la LRAU, una diferenciación de los derechos de la 
propiedad en lo que se refiere a las llamadas "cesiones de aprovechamiento" (el famoso $10 \%{ }^{1}$ ). Porque en cuanto a la gestión se refiere, no hay distinción en los trámites para la adjudicación de un Programa de actuación integrada, ya sea en ámbitos de suelo urbano o urbanizable.

El mayor aspecto diferencial en lo concerniente a las adjudicaciones en competencia, entre ámbitos de suelo urbano y urbanizable, sería el tamaño, como podemos comprobar en la FIG. 7. La mayor edificabilidad de un sector se convirtió en el principal atractivo para que los agentes, independientemente de su participación en la estructura de la propiedad, optasen por la vía de la urbanización para mejorar su posición en el mercado de suelo o buscasen asegurarse un mayor control sobre los plazos de ejecución.

Figura $N^{\circ}$ 7: Grado de competencia entre $\mathrm{P}$ J-E en términos de edificabilidad total por unidades de ejecución (UE)

\begin{tabular}{|c|c|c|}
\hline \multirow[b]{2}{*}{ Tramos por techo $\left(\mathrm{m}^{2} \mathrm{t}\right)$} & \multicolumn{2}{|c|}{ Adjudicaciones } \\
\hline & UE & $\begin{array}{c}\text { UE con } \\
\text { competencia } \\
\text { entre PJ-E }\end{array}$ \\
\hline Hasta 25.000 & 21 & 6 \\
\hline 25.001 a 50.000 & 8 & 3 \\
\hline 50.001 a 100.000 & 5 & 2 \\
\hline 100.001 a 200.000 & 5 & 1 \\
\hline Mayor de 200.000 & 8 & 4 \\
\hline
\end{tabular}

Fuente: Elaboración propia

Por otra parte, la existencia de planeamiento detallado aprobado con anterioridad a la convocatoria de los concursos, no se convirtió en un incentivo adicional para la presentación de plicas (contrariamente a lo que cabría suponer) pese a conocerse de antemano un factor fundamental como es la ordenación, para definir con cierta fiabilidad la urbanización y sus costes. De las 30 actuaciones tramitadas por gestión indirecta en las que existía una ordenación pormenorizada aprobada con anterioridad, tan sólo en un tercio de los casos se presentó más de una plica optando por su ejecución (Fig. 8).

\footnotetext{
${ }^{1}$ Recomendamos la lectura del ejercicio de síntesis realizado por José María Nogueira en su artículo "El suelo y la vivienda", El País - Negocios, 22 de octubre de 2005.
} 
Figura Nº 8: Ámbitos de actuación, situación del planeamiento y plicas

\begin{tabular}{|c|c|c|c|}
\hline \multicolumn{3}{|r|}{ ACTUACIÓN } & U.E. \\
\hline \multirow{2}{*}{\multicolumn{2}{|c|}{$\begin{array}{ll}\text { UA } & 10\end{array}$}} & \multirow{2}{*}{ Ciutat Jardí } & UA 10 I- I \\
\hline & & & UA 10-II \\
\hline UA & 18 & Unifamiliar Albufereta & Única \\
\hline UA & 19 & El Grillo & Única \\
\hline$\overline{U A}$ & 20 & El Camping & Única \\
\hline UA & 23 & Cala Cantalar & Única \\
\hline UA & 30 & Villafranqueza Norte & Única \\
\hline UA & 33 & P. América - Campoamor & Única \\
\hline UE & & CC/ Haroldo Parres, Dr. S & Única \\
\hline
\end{tabular}

\begin{tabular}{|r|r|r|}
\hline \multicolumn{1}{|c|}{$\mathrm{m}^{2} \mathrm{~s}$} & \multicolumn{1}{c|}{$\mathrm{m}^{2} \mathrm{t}$} & \multicolumn{1}{l|}{ Viv. } \\
\hline 45.133 & 12.189 & 41 \\
\hline 23.486 & 6.791 & 23 \\
\hline 59.550 & 14.160 & 30 \\
\hline 9.500 & 4.732 & 39 \\
\hline 64.840 & 23.492 & 196 \\
\hline 102.420 & 21.174 & 176 \\
\hline 26.736 & 27.770 & 231 \\
\hline- & - & - \\
\hline 1.646 & \multicolumn{1}{|c|}{5.293} & 44 \\
\hline
\end{tabular}

\begin{tabular}{|c|c|c|c|}
\hline ORD \\
\hline$\bullet$ \\
\hline$\bullet$ \\
\hline$\bullet$ \\
\hline$\bullet$ \\
\hline 1 & AT & PJ-E & PAI \\
\hline 2 & 2 & 1 \\
\hline 1 & 1 & 1 \\
\hline 2 & 3 & 2 \\
\hline$\bullet$ \\
\hline 1 & 1 & 1 \\
\hline 1 & 1 & 1 \\
\hline$\bullet$ \\
\hline 1 & 1 & 1 \\
\hline 1 & 1 & 1 \\
\hline 1 & 1 & 1 \\
\hline
\end{tabular}

\begin{tabular}{|c|c|c|c|}
\hline APD & 3 & Tómbola & UA/II \\
\hline APD & 5 & C/ Diagonal & - \\
\hline \multirow[t]{4}{*}{ APD } & \multirow[t]{4}{*}{7} & \multirow{4}{*}{ Cerámica Los Angeles } & UA / II \\
\hline & & & UA/IV \\
\hline & & & UA/V \\
\hline & & & $\mathrm{UA} / \mathrm{VI}$ \\
\hline APD & 8 & Depósitos & $\mathrm{UA} / 2$ \\
\hline APD & 9 & C/ Finestrat & UA / IV \\
\hline APD & 11 & Babel - C/Asilo & Única \\
\hline APD & 21 & Área del transporte & Única \\
\hline APD & 22 & Babel Sur & Polg. III \\
\hline APD & 25 & Benalúa Sur & Única \\
\hline
\end{tabular}

\begin{tabular}{|r|r|r|}
\hline 22.144 & 16.587 & 127 \\
\hline 21.298 & 39.526 & 304 \\
\hline 12.994 & 15.950 & 100 \\
\hline 2.880 & 5.080 & 25 \\
\hline 1.905 & 3.010 & 12 \\
\hline 3.463 & 4.550 & 24 \\
\hline 3.727 & 10.760 & 90 \\
\hline 2.766 & 7.575 & 60 \\
\hline 8.357 & 15.400 & 110 \\
\hline 338.420 & 338.420 & 0 \\
\hline 16.200 & 17.562 & 123 \\
\hline 16.836 & 40.905 & 202 \\
\hline
\end{tabular}

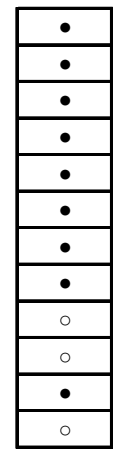

\begin{tabular}{|l|l|l|}
\hline 1 & 2 & 2 \\
\hline 1 & 1 & 1 \\
\hline 1 & 1 & 1 \\
\hline 1 & 1 & 1 \\
\hline 1 & 1 & 1 \\
\hline 1 & 1 & 1 \\
\hline 1 & 1 & 1 \\
\hline 1 & 1 & 1 \\
\hline 1 & 1 & 1 \\
\hline 1 & 1 & 1 \\
\hline 1 & 1 & 1 \\
\hline 2 & 2 & 2 \\
\hline
\end{tabular}

\begin{tabular}{|c|c|c|}
\hline PE/APA 7 & Terciario Bon Hivern & Única \\
\hline \multirow[t]{6}{*}{ PE/APA 8} & \multirow[t]{6}{*}{ Garbinet } & Polg. I \\
\hline & & Polg. VIII \\
\hline & & Polg. X \\
\hline & & Polg. XII \\
\hline & & Polg. XV \\
\hline & & Polg. XVII \\
\hline \multirow[t]{2}{*}{ PE/APA 9} & \multirow[t]{2}{*}{ Vistahermosa } & Polg. 9 \\
\hline & & Resto PP \\
\hline PE/APA 10 & Vistahermosa-Goteta & Polg. III \\
\hline
\end{tabular}

\begin{tabular}{|r|r|r|}
\hline 101.100 & 63.742 & 66 \\
\hline 14.435 & 12.720 & 110 \\
\hline 46.793 & 38.880 & 338 \\
\hline 20.832 & 15.583 & 160 \\
\hline 73.023 & 58.008 & 585 \\
\hline 37.331 & 27.894 & 270 \\
\hline 33.529 & 26.715 & 240 \\
\hline 26.845 & 19.665 & 51 \\
\hline 727.435 & 233.484 & 1.472 \\
\hline 55.860 & 26.308 & 427 \\
\hline
\end{tabular}

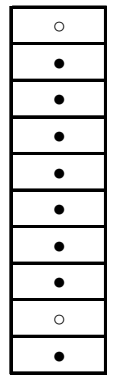

\begin{tabular}{|l|l|l|}
\hline 1 & 1 & 1 \\
\hline 1 & 1 & 1 \\
\hline 2 & 2 & 1 \\
\hline 2 & 2 & 1 \\
\hline 1 & 1 & 1 \\
\hline 1 & 1 & 1 \\
\hline 1 & 1 & 1 \\
\hline 2 & 2 & 1 \\
\hline 3 & 3 & 1 \\
\hline 2 & 2 & 1 \\
\hline
\end{tabular}

\begin{tabular}{|cr|l|c|}
\hline PP & I/1 & Fàbrica de sacos & Polg. 1 \\
\hline PP & I/2 & Benalúa Sur & $\mathrm{UE} / 1$ \\
\hline PP & I/3 & Industrial C/Trento & $\mathrm{UE} / 1$ \\
\cline { 4 - 4 } & & & $\mathrm{UE} / 2$ \\
\hline PP & I/4 & Albufereta & Polg. A \\
\hline PP & I/6 & Platja St. Joan & $\mathrm{UE} / 1$ \\
\cline { 4 - 4 } & & $\mathrm{UE} / 2$ \\
\hline PP & II/8 & Los Ángeles & Polg. 2 \\
\hline PP & & Agua Amarga - OAMI & Única \\
\hline
\end{tabular}

\begin{tabular}{|r|r|r|}
\hline 6.287 & 7.294 & 61 \\
\hline 74.168 & 83.127 & 597 \\
\hline 42.544 & 51.902 & 0 \\
\hline 82.187 & 119.485 & 0 \\
\hline 173.991 & 190.757 & 1.590 \\
\hline 308.335 & 280.930 & 1.712 \\
\hline 179.186 & 159.291 & 1.253 \\
\hline 38.571 & 22.367 & 186 \\
\hline 199.502 & 115.000 & - \\
\hline
\end{tabular}
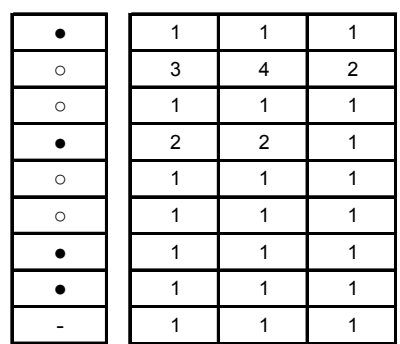

\begin{tabular}{|lr|l|c|}
\hline PAU & $\mathbf{1}$ & & Única \\
\hline PAU & $\mathbf{3}$ & & Única \\
\hline PAU & $\mathbf{4}$ & La Condomina & UE/ 1 \\
\hline PAU & $\mathbf{5}$ & San Juan Norte & Sector 1 \\
\cline { 4 - 4 } & & & Sector 2 \\
\hline
\end{tabular}

\begin{tabular}{|r|r|r|}
\hline 712.987 & 429.100 & 3.625 \\
\hline 689.639 & 278.767 & 1.772 \\
\hline 2.249 .181 & 628.498 & 5.922 \\
\hline 692.674 & 351.200 & 3.333 \\
\hline 128.617 & 96.124 & 825 \\
\hline
\end{tabular}

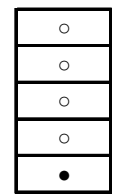

\begin{tabular}{|l|l|l|}
\hline 3 & 3 & 1 \\
\hline 3 & 4 & 3 \\
\hline 1 & 1 & 1 \\
\hline 2 & 2 & 1 \\
\hline 2 & 2 & 1 \\
\hline
\end{tabular}

Ámbitos según PG de Alicante (1987)

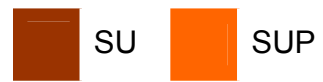

SUNP SNU

NOTA: La columna "ORD" muestra la situación del planeamiento en el momento de la apertura del concurso de adjudicación de PAl, indicando "•" los casos en los que la ordenación pormenorizada estaba aprobada con anterioridad. 


\section{2.b Posibles explicaciones sobre la falta de competencia}

Entonces, ¿a qué se debe la escasez de competencia explícita en las adjudicaciones de Programas? Para buscar los argumentos que contribuyan a explicar estos resultados nos fijaremos en la evolución temporal de la participación de los agentes a través de un seguimiento anual de las adjudicaciones.

1. Los primeros años restan.

El análisis de las actuaciones adjudicadas indica que la competencia explícita no apareció en los procesos de adjudicación hasta los 3 años de vigencia de la LRAU. Interpretamos este hecho como resultado de las condiciones heredadas de la situación anterior a 1994, donde ya se inició la tramitación de diversas actuaciones (aunque no existiera un compromiso efectivo todavía para su ejecución) y en las que las posiciones sobre la propiedad del suelo eran ya muy avanzadas. Destaca en este sentido la adjudicación en febrero de 1996 de la unidad de ejecución $n^{\circ} 1$ del PAU-4, que representa una de las mayores urbanizaciones de Alicante con $628.500 \mathrm{~m}^{2} \mathrm{t}$. En dicha ocasión tan sólo se presentó una plica, correspondiente al grupo que ostentaba la titularidad del $80 \%$ de los terrenos.

Figura ํ 9: Evolución del grado de competencia explícita por años

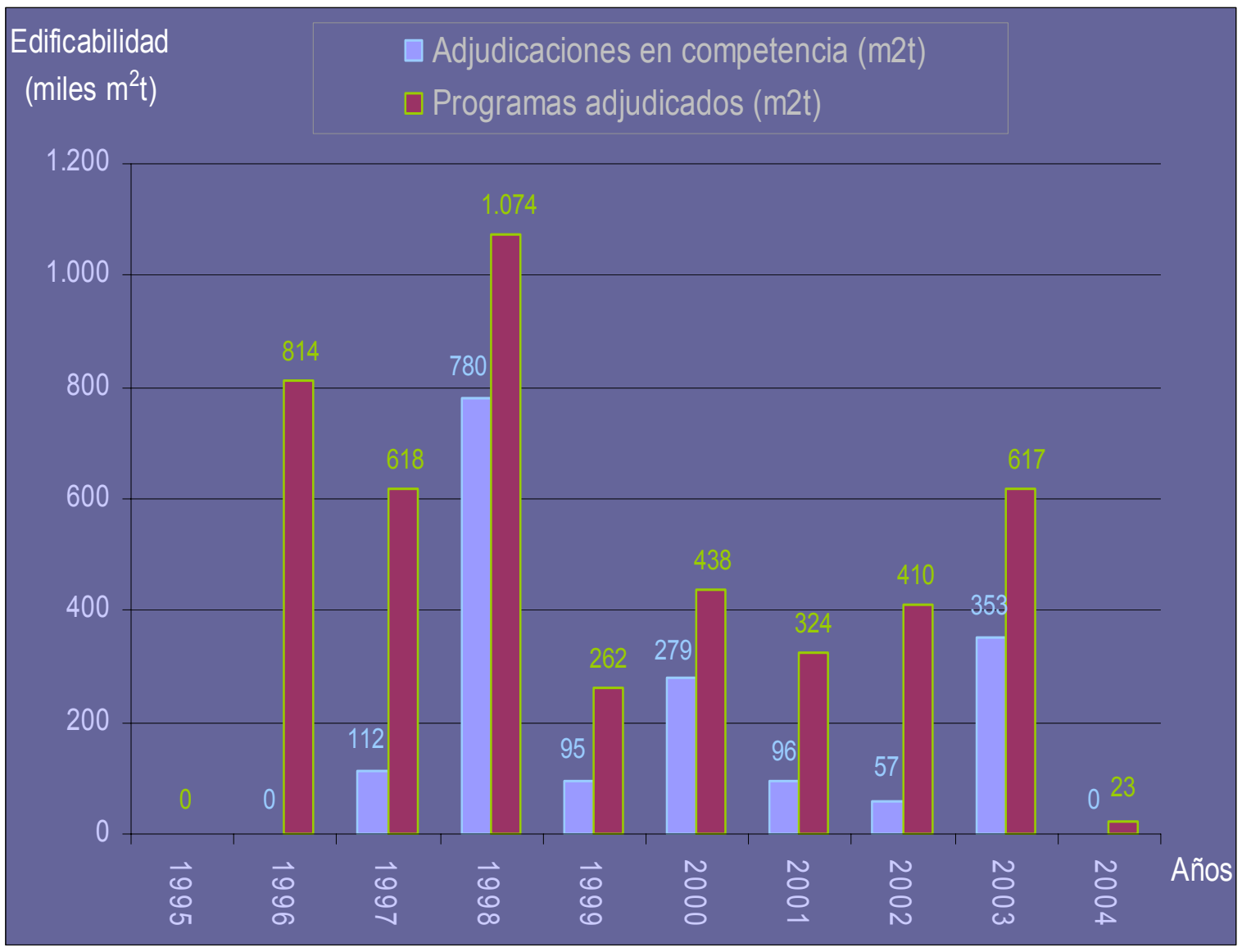

Fuente: Elaboración propia 
Analizando las pautas de comportamiento una vez pasados los primeros años de implantación de la LRAU, observaremos un cierto aumento del grado de competencia en los procesos de adjudicación. Por lo tanto, fijándonos únicamente en la participación desde 1998 encontramos que la media del nivel de competencia en las actuaciones aprobadas se sitúa en un $47 \%$, que supone una mejora respecto al $35,6 \%$ global, pero que podemos seguir considerando como un nivel bajo.

\section{Comportamiento de los agentes.}

Otro aspecto que puede acercarnos a comprender el porqué del bajo grado de competencia podemos encontrarlo en las pautas de comportamiento de los aspirantes a convertirse en agentes urbanizadores. Veamos lo ocurrido a partir del resumen siguiente.

\section{Figura $\mathrm{N}^{\circ}$ 10: Comportamiento de los agentes aspirantes a adquirir la condición de Urbanizador}

$N^{\circ}$ de agentes participantes

\begin{tabular}{|l|c|}
\hline Alternativa Técnica (AT) & 41 \\
\hline Proposición Jurídico-Económica (P J-E) & 44 \\
\hline P.J-E a la AT aprobada & 37 \\
\hline
\end{tabular}

Comportamiento de los agentes

\begin{tabular}{|c|c|c|c|c|c|c|c|c|c|c|c|c|}
\hline \multicolumn{13}{|c|}{ Comportamiento en relación a la presentación de Alternativas Técnicas (AT) } \\
\hline Presentan AT & 33 & 4 & 2 & 0 & 2 & 41 & $80,5 \%$ & $9,8 \%$ & $4,9 \%$ & $0,0 \%$ & $4,9 \%$ & $100,0 \%$ \\
\hline Cuya(s) AT resulta(n) aprobada(s) & 27 & 2 & 2 & 0 & 1 & 32 & $65,9 \%$ & $4,9 \%$ & $4,9 \%$ & $0,0 \%$ & $2,4 \%$ & $78,0 \%$ \\
\hline
\end{tabular}

\begin{tabular}{|c|c|c|c|c|c|c|c|c|c|c|c|c|}
\hline \multicolumn{13}{|c|}{ Comportamiento en relación a la presentación de Proposiciones Jurídico-Económicas (P J-E) } \\
\hline Número de agentes & 1 & 2 & 3 & 4 & $\geq 5$ & Total & 1 & 2 & 3 & 4 & $\geq 5$ & Total \\
\hline Presentan P.J-E & 33 & 6 & 3 & 0 & 2 & 44 & $75,0 \%$ & $13,6 \%$ & $6,8 \%$ & $0,0 \%$ & $4,5 \%$ & $100,0 \%$ \\
\hline Cuya P J-E resulta aprobada & 28 & 2 & 2 & 0 & 1 & 33 & $63,6 \%$ & $4,5 \%$ & $4,5 \%$ & $0,0 \%$ & $2,3 \%$ & $75,0 \%$ \\
\hline
\end{tabular}

\begin{tabular}{|c|c|c|c|c|c|c|c|c|c|c|c|c|}
\hline \multicolumn{13}{|c|}{ Comportamiento en relación a la presentación de P.J-E a la AT aprobada (PAI) } \\
\hline Presentaron P.J-E a AT aprobada & 32 & 3 & 2 & 0 & 1 & 38 & $84,2 \%$ & $7,9 \%$ & $5,3 \%$ & $0,0 \%$ & $2,6 \%$ & $100,0 \%$ \\
\hline Adjudicatarios de PAls & 28 & 2 & 2 & 0 & 1 & 33 & $73,7 \%$ & $5,3 \%$ & $5,3 \%$ & $0,0 \%$ & $2,6 \%$ & $86,8 \%$ \\
\hline
\end{tabular}

Fuente: Elaboración propia 
De los 38 agentes que mantuvieron opciones efectivas en la fase de adjudicación de Programa, al competir por la ejecución de la alternativa técnica aprobada, fueron finalmente 33 los que obtuvieron la condición de Urbanizador al resultar ganadoras sus plicas.

Es decir, estos 33 agentes llevaron a cabo la ejecución de las 45 actuaciones en gestión indirecta. Como se pone de manifiesto en la FIG. 10, la mayoría (75\%) de los 44 agentes que formularon alguna propuesta de ejecución, sólo presentaron plica a una única unidad de ejecución cada uno. O lo que es lo mismo, fueron escasos (11) los agentes que buscaron urbanizar diversas actuaciones.

En concreto, tan sólo dos pujaron por resultar adjudicatarios en al menos 5 de las 45 actuaciones gestionadas por particulares o empresas.

Observamos por tanto que la mayoría de los agentes urbanizadores participantes en los procesos de ejecución de planes en el municipio de Alicante, lo hicieron de forma esporádica. Al fijarnos en los sujetos que presentaron sus plicas en más de tres actuaciones obtenemos que es muy escaso (6\%) el número de agentes actuando en Alicante que hayan hecho de la gestión del planeamiento de este municipio una parte constante de su volumen de negocio. Es decir, hubo muchos urbanizadores pero la mayoría de ellos intervino muy esporádicamente (alrededor del $80 \%$ de los agentes sólo participó en un concurso).

Ahora bien, si llevamos nuestro análisis más allá del indicador "participación" ¿cómo quedó atribuido el reparto de la función urbanizadora? Tomando como referencia la edificabilidad correspondiente a cada unidad de ejecución, se deduce que 3 de los 33 agentes designados como urbanizadores ejecutaron los ámbitos correspondientes al 52,21 \% del techo total gestionado a través de PAls. Por tanto fueron escasos los agentes que hicieron de la urbanización una parte de su negocio.

Dado el gran número de agentes urbanizadores deducimos que fue la propiedad inicial de suelo el factor principal que sirvió de estímulo para su participación.

3.2.c Resultados de la ejecución en términos de la competencia por la gestión

Nos planteamos analizar en este caso si se produjeron diferencias en los resultados de la gestión, cuando las actuaciones fueron ejecutadas por agentes elegidos en circunstancias de competencia explícita o cuando se adjudicaron a propuestas recibidas en solitario. Antes de abordar esta cuestión veamos resumidamente las cifras globales de la ejecución del Plan General de Alicante. 
Figura $N^{\circ}$ 11: Resultados globales de la ejecución con la LRAU expresados en tiempo y en coste, desde diciembre de 1994 hasta agosto de 2005 (ambos inclusive)

\begin{tabular}{|c|c|c|c|c|c|c|}
\hline & UA & APD & PE/APA & PP & PAU & TOTAL \\
\hline \multicolumn{6}{|c|}{ Aprobación } & \\
\hline Definitiva & 11 & 12 & 12 & 13 & 3 & 51 \\
\hline Provisional & 0 & 2 & 0 & 0 & 2 & 4 \\
\hline \multicolumn{7}{|c|}{ Uso característico } \\
\hline Residencial & 10 & 13 & 11 & 11 & 5 & 50 \\
\hline Industrial / Terciario & 1 & 1 & 1 & 2 & 0 & 5 \\
\hline \multicolumn{7}{|c|}{ Gestión } \\
\hline Indirecta & 11 & 13 & 12 & 11 & 5 & 52 \\
\hline Directa & 0 & 1 & 0 & 2 & 0 & 3 \\
\hline \multicolumn{7}{|c|}{ Redacción planeamiento } \\
\hline Municipal & 10 & 9 & 1 & 11 & 0 & 31 \\
\hline Autonómico & 0 & 1 & 0 & 2 & 0 & 3 \\
\hline Particulares & 1 & 4 & 11 & 0 & 5 & 21 \\
\hline \multicolumn{6}{|c|}{ Tamaño medio } & Promedio \\
\hline Superficie (Ha) & 4,68 & 5,78 & 12,77 & 14,49 & 87,33 & 25,01 \\
\hline Edificabilidad $\left(\mathrm{m}^{2} \mathrm{t}\right)$ & 24.165 & 38.327 & 47.659 & 119.441 & 356.738 & 117.266 \\
\hline \multicolumn{6}{|c|}{ Plazos medios (meses) } & Promedio \\
\hline $\begin{array}{l}\text { Inf. Pública- } \\
\text { Aprobación }\end{array}$ & 20 & 20 & 17 & 34 & $35^{*}$ & 25 \\
\hline $\begin{array}{c}\text { Aprobación-Inicio } \\
\text { obras }\end{array}$ & 16 & 22 & 23 & 21 & $32^{*}$ & 23 \\
\hline \multicolumn{6}{|c|}{ Promedio cargas actualizado $(€)$ a septiembre de 2005} & Promedio \\
\hline Programa & $932.401 €$ & $2.223 .895 €$ & $5.012 .388 €$ & $6.119 .589 €$ & $41.343 .249 €$ & 11.126.304€ \\
\hline Coste obras & - & $1.552 .000 €$ & $3.219 .278 €$ & $3.452 .262 €$ & $21.931 .098 €$ & $7.538 .660 €$ \\
\hline
\end{tabular}

* Excluyendo el PAU-4, Fuente: Elaboración propia

Los parámetros de comparación corresponden a situaciones distintas con relación al momento del acuerdo municipal de adjudicación. Por un lado examinamos datos que explican pautas de comportamiento de los agentes en la fase de concurso (con anterioridad a la adjudicación) a través del contenido de las propuestas que resultaron elegidas. Nos referimos en este sentido a los compromisos adquiridos por los diferentes agentes urbanizadores en relación a los costes de urbanización, a las garantías que ofrecieron y, adicionalmente, a la ejecución de viviendas con algún régimen de protección. También en este apartado de proposiciones nos fijamos en los beneficios a los que aspiraban y que fueron acordados con la adjudicación del Programa. Los parámetros utilizados se ajustan a los criterios dictados en el art. 47 de la LRAU ${ }^{2}$ para la

2 Art. 47.2 LRAU: "Se preferirá la alternativa que proponga un ámbito de actuación más idóneo u obras de urbanización más convenientes; la que concrete y asuma las más adecuadas calidades de obra para su ejecución; así como la 
adjudicación motivada de los Programas, estableciéndose en los apartados segundo y tercero los aspectos que deben guiar la decisión pública de programación

En concreto, analizamos el efecto de la existencia de competencia explícita (variable independiente) en los procesos de adjudicación, por medio de las siguientes variables dependientes:

a) Costes de urbanización (obras)

b) Beneficio del urbanizador y gastos de gestión

c) Garantías ofrecidas

d) Compromisos adicionales: vivienda protegida

Por otro lado observamos los hechos sucedidos con posterioridad al acuerdo de programación analizando los resultados temporales de las tramitaciones que siguen a adjudicaciones con competencia o sin ella:

e) Plazos de tramitación

Asumiendo que la decisión de Pleno siguió criterios coherentes para la elección, en cada uno de los casos, de la mejor de las opciones de programación, nos proponemos evaluar si el hecho de que se presentasen una sola plica o varias en competencia, se trasladó a los resultados de la gestión.

\section{a) COSTES DE URBANIZACIÓN}

Un aspecto clave para la determinación de las cargas es el de los costes de urbanización. Estos dependen básicamente de las soluciones técnicas de proyecto y de las calidades de obra, reflejadas en valores unitarios en función de la base de precios escogida. Debemos, en primer lugar, ajustar con precisión el manejo de la variable costes para poder realizar un análisis comparativo entre operaciones distintas.

En nuestro caso, analizamos la incidencia de los costes de la obra de urbanización por superficie de ámbito. Teniendo en cuenta la singularidad de las actuaciones que pretendemos comparar, hemos de procurar limitar el grado de heterogeneidad entre los diferentes casos, ajustando los parámetros de comparación. Para ello recurrimos a una doble estrategia:

a) En lo que se refiere a la variable "costes de urbanización" optamos por extraer las partidas que introducen más variaciones en el presupuesto final de obra por factores no atribuibles a la propia calidad de la obra. Retiramos por tanto todos los costes de conexión exterior, los costes de demolición y de movimiento de tierras (estos últimos muy variables en un municipio de topografía accidentada como la de Alicante), las obras de saneamiento (respecto a las que existían grandes diferencias en la situación de partida) y el gas (no todos los ámbitos lo incluyen). Entonces consideramos las

proposición que se obligue a plazos de desarrollo más breves o a compromisos más rigurosos; la que preste mayores garantías efectivas de cumplimiento; la que comprometa su realización asumiendo, expresa y razonadamente, un beneficio empresarial más proporcionado por la promoción y gestión de la Actuación; o la que prevea justificadamente, para unas mismas obras, un menor precio máximo para efectuarlas sin mengua de su calidad. Complementariamente se preferirá la proposición que oferte más incentivos, garantías o posibilidades de colaboración de los propietarios afectados por la Actuación, para facilitar o asegurar su desarrollo, salvo que aquellos se pretendan arbitrar a costa del interés público." 
partidas de obra civil urbanística que permitirán establecer un precio unitario comparable.

b) Teniendo en cuenta que lo dispuesto en cada plan genera un porcentaje variable de superficie a urbanizar, y ésta viene fijada reglamentariamente en función de los índices de densidad edificable, tomamos como unidad de medida la superficie estrictamente urbanizable en cada actuación. Es decir, consideramos la superficie de espacio público (viario y zonas libres) que será proporcional a la edificabilidad atribuida a cada sector. Bien es cierto que los requisitos de estándares mínimos de dotaciones (y de viales de acuerdo con el Reglamento de Planeamiento de la Comunidad Valenciana, de aplicación con la LRAU) se aplican a los ámbitos de planeamiento, y no se realiza este cómputo en los ámbitos de gestión. En cualquier caso, para limitar todavía más el posible margen de error, hemos optado por considerar los datos de las superficies efectivas de vial y de zona verde pública correspondientes a cada unidad de ejecución.

Resumiendo, comparamos costes, debidamente actualizados a fecha de septiembre de 2005 según la evolución del IPC en la provincia de Alicante, por unidad de superficie de espacio público a urbanizar.

Una vez fijados los criterios de comparación fueron 21 las muestras de actuaciones donde los datos presentaban el grado de homogeneidad adecuado.

\section{Figura № 12: Coste de urbanización uniformizado por unidad de superficie urbanizada}

\begin{tabular}{|l|l|l|}
\cline { 2 - 3 } \multicolumn{1}{c|}{} & $\begin{array}{l}\text { Coste urbanización } \\
\text { (actualizado Sep-05) }\end{array}$ & N$^{\circ}$ muestras \\
\hline Sin competencia & $51,43 € / \mathrm{m} 2 \mathrm{~s}$ & 10 \\
\hline Con competencia & $54,54 € / \mathrm{m} 2 \mathrm{~s}$ & 11 \\
\hline
\end{tabular}

Fuente: Elaboración propia

¿Qué comparamos en nuestro análisis? La LRAU determina en su artículo 47 los criterios de adjudicación y dispone, en relación con las obras de urbanización, que se preferirán las más idóneas para el servicio público. Dado que queremos comparar los resultados de los proyectos aprobados, cuyas condiciones de ordenación son distintas, debemos establecer un criterio uniforme para nuestra comparación. Si tomamos como punto de partida el propio proyecto urbanístico (la ordenación), la preferencia municipal se orientará, por regla general, hacia las alternativas más costosas (más espacios públicos urbanizados y con mejores calidades de obra). Sin embargo, un segundo criterio referido a los costes desde el punto de vista de la gestión iría en la dirección opuesta. Dicho de otro modo, el acuerdo municipal optará por el Programa de Actuación Integrada que ofrezca el producto (proyecto) más costoso, con la propuesta para ejecutarlo (gestión) más ajustada en cuanto a los costes de producción. Es decir, el objetivo es obtener más para la colectividad al menor coste.

Asumiendo que todas las propuestas técnicas de las actuaciones a ejecutar debieron superar el exigente y uniforme criterio técnico municipal, optamos por comparar la variable "diseño" de las apuestas empresariales que compitan por la urbanización. Así, nuestra comparación se 
circunscribe, en el caso de los costes de urbanización, sólo a las opciones de proyecto escogidas (el producto) y no a la capacidad empresarial para su gestión, aspecto que trataremos a continuación al analizar los beneficios y gastos empresariales del urbanizador. De este modo, los resultados anteriores apuntan hacia una ligera mejoría de las calidades mediante la competencia. En cualquier caso fueron escasas las diferencias entre actuaciones adjudicadas con competencia explícita o sin ella.

\section{b) BENEFICIO DEL URBANIZADOR y GASTOS DE GESTIÓN}

El concepto de beneficio del urbanizador puede llevar a confusión, si se identifica con el beneficio del agente urbanizador, que forma parte de los costes de producción de suelo urbanizado. En realidad, al analizar el beneficio del urbanizador nos referimos al concepto establecido por la LRAU en el Art. 67.1.D donde se define como una carga de urbanización derivada de la actividad promotora de la urbanización. Se trata por tanto, de la rentabilidad empresarial de la inversión (FERNÁNDEZ et al., 2003).

En lo relativo a los gastos de gestión, también incluidas en el referido apartado $D$ del Art. 67.1 de la LRAU, este concepto engloba aquellos gastos derivados de la organización de medios humanos y materiales requeridos por la actividad empresarial de producción y transformación de suelo.

En este caso, analizamos la repercusión del beneficio del urbanizador por unidad de superficie de suelo dotacional público a urbanizar. Se muestran los gastos de gestión conjuntamente con el beneficio del urbanizador, dado que estos conceptos se presentaron unidos en el detalle de las cargas de urbanización de gran parte de las proposiciones jurídico-económicas muestreadas.

Figura $N^{\circ} 13$ : Beneficio del urbanizador y gastos de gestión respecto al suelo a urbanizar

\begin{tabular}{lll} 
& \multicolumn{1}{c}{$\begin{array}{c}\text { B.urb }+ \text { G.G. } \\
\text { suelo a urbanizar }\end{array}$} & $\begin{array}{l}\text { Número de } \\
\text { muestras }\end{array}$ \\
\hline Sin competencia & $7,07 € / \mathrm{m}^{2} \mathrm{~s}$ & 14 \\
\hline Con competencia & $5,52 € / \mathrm{m}^{2} \mathrm{~s}$ & 11
\end{tabular}

Fuente: Elaboración propia

En este caso aparecen diferencias significativas que indican una reducción de estas cargas en los casos donde sí existió competencia explícita. Recordemos que, en la mayoría de los casos, la competencia explícita se producía en situaciones de suelo urbanizable y especialmente en las operaciones de mayor dimensión. Se trata por tanto de operaciones donde, a priori, los agentes participantes no partían de una gran tenencia de suelo y cuyo perfil se ajusta más al del empresario inmobiliario profesional. 


\section{c) GARANTÍAS}

El análisis de las garantías ofrecidas por los proponentes en sus respectivas plicas muestra unos resultados todavía más claros: en el $90 \%$ de los casos las garantías prestadas por el urbanizador se limitaron a los mínimos establecidos por la ley.

\section{d) VIVIENDA PROTEGIDA}

En lo referente a la oportunidad de proponer la realización de vivienda con algún régimen de protección pública, aspecto respecto al que la LRAU no establecía mínimos, los agentes no optaron por acudir a esta posibilidad como compromiso adicional con el que mejorar sus propuestas.

\section{e) PLAZOS}

Por último, planteamos una comparación de los plazos de ejecución entre actuaciones con competencia explícita y sin ella, analizando dos períodos. El primer período evaluado comporta el inicio de procedimiento hasta la fecha de aprobación, mientras que el segundo corresponde a la fase que transcurre desde la aprobación del Programa hasta el inicio de las obras.

Nuestra comparación requiere concretar algunos matices. En lo que respecta a los tiempos parciales que llevan desde la apertura del procedimiento con la fase de información pública hasta la aprobación definitiva, se debe considerar el hecho de que no todas las actuaciones contaban con planeamiento detallado aprobado en el momento de la aprobación del Programa. Incluso estando definida de antemano la ordenación pormenorizada, también pueden darse modificaciones de las determinaciones de rango estructural, lo que trae como consecuencia una lógica extensión de los plazos, por el requisito del visto bueno de la Conselleria competente en materia de urbanismo.

Como vemos, el análisis de la variable 'tiempo' resulta dificultoso dada la heterogeneidad de las circunstancias en que se sitúan las actuaciones. Veamos resumidamente las condiciones generales de las actuaciones muestreadas.

Figura $\mathrm{N}^{\circ}$ 14: Variable plazos: síntesis de las actuaciones analizadas

\begin{tabular}{|c|c|c|c|c|c|}
\hline & \multirow[b]{2}{*}{$\begin{array}{l}\text { Actuaciones } \\
\text { analizadas }\end{array}$} & \multirow[b]{2}{*}{$\begin{array}{l}\text { Ordenación } \\
\text { detallada }\end{array}$} & \multicolumn{3}{|c|}{ Tamaño medio } \\
\hline & & & Superficie & Techo & Viviendas \\
\hline $\begin{array}{l}\text { SIN } \\
\text { COMPETENCIA }\end{array}$ & 22 & 17 & $15,5 \mathrm{Ha}$ & $72.000 \mathrm{~m}^{2} \mathrm{t}$ & 600 \\
\hline $\begin{array}{l}\text { CON } \\
\text { COMPETENCIA }\end{array}$ & 13 & 9 & $22,0 \mathrm{Ha}$ & $110.200 \mathrm{~m}^{2} \mathrm{t}$ & 870 \\
\hline
\end{tabular}

Fuente: Elaboración propia

Como es lógico, la existencia de la ordenación detallada con anterioridad a la tramitación de un PAI repercute en los plazos desde la apertura del período de información pública hasta la aprobación definitiva del Programa, junto al correspondiente instrumento de planeamiento. 
Figura No 15: Plazos de tramitación en actuaciones residenciales con gestión indirecta

\begin{tabular}{l|ll|ll|} 
& \multicolumn{2}{|l|l}{$\begin{array}{l}\text { SIN } \\
\text { competencia } \\
\text { explícita }\end{array}$} & $\begin{array}{l}\text { CON } \\
\text { competencia } \\
\text { explícita }\end{array}$ \\
\hline Información pública - Aprobación & 18,4 & {$[20]$} & 27,1 & {$[13]$} \\
\hline Aprobación - Inicio obras & $\mathbf{2 1 , 0}$ & {$[14]$} & $\mathbf{2 2 , 8}$ & {$[7]$} \\
\hline Total & 39,4 & & 49,9 &
\end{tabular}

Fuente: Elaboración propia

A la vista de los resultados se comprueba que los plazos de tramitación, una vez comprometida la programación, son similares en los casos donde se presentaron diversas plicas y en los que sólo hubo una candidatura para llevar a cabo la urbanización. Hemos realizado este análisis tomando como muestra el total de unidades de las que disponíamos de datos, sin hacer distinciones, lo que comporta sin duda una influencia determinante de las terceras variables. Seguidamente llevamos a cabo el mismo análisis limitando las unidades a aquellas que implican una producción mayor a 100 viviendas en cada caso.

Figura N 16: Plazos de tramitación en actuaciones mayores a 100 viviendas

\begin{tabular}{l|ll|ll|} 
TIEMPO (meses) & \multicolumn{2}{|l|l}{$\begin{array}{l}\text { SIN } \\
\text { competencia } \\
\text { explícita }\end{array}$} & $\begin{array}{l}\text { CON } \\
\text { competencia } \\
\text { explícita }\end{array}$ \\
\hline Información pública - Aprobación & 17,2 & {$[12]$} & 29,5 & {$[9]$} \\
\hline Aprobación - Inicio obras & $\mathbf{1 9 , 1}$ & {$[11]$} & $\mathbf{2 4 , 6}$ & {$[6]$} \\
\hline Total & 36,3 & 53,7 &
\end{tabular}

NOTAS:Las cifras ente corchetes indican el número de unidades muestrales empleadas para el análisis.

La fecha de aprobación a la que se hace referencia corresponde a la de la aprobación definitiva. Fuente: Elaboración propia

En este caso, sí resulta apreciable una diferencia de los plazos totales de tramitación de las operaciones adjudicadas con competencia y sin ella. Este aspecto es más evidente aún si incorporamos a nuestro estudio dos importantes operaciones (PAU-3 y PAU-5, unidad 2) que se encontraban, en el momento de la tomas de datos, en una fase avanzada de tramitación para su aprobación definitiva. Agregando estos casos, el tiempo inicial medio que lleva a la aprobación del Programa (fijada hipotéticamente en la fecha de este estudio) se incrementa hasta los 40 meses en el supuesto de operaciones tramitadas con competencia. Atendiendo únicamente a los plazos con carácter legalmente vinculante (garantizados en el momento de la adjudicación) comprendidos entre la aprobación definitiva del Programa y el inicio de las obras también resulta llamativa la diferencia entre los supuestos con competencia y sin ella, 
resultando más lenta la urbanización llevada a cabo tras una adjudicación entre diversas plicas concurrentes.

Por lo tanto, los resultados indican que la existencia de competencia explícita en los procesos de adjudicación de Programas no se tradujo necesariamente en una reducción de los plazos de ejecución del planeamiento. Estos resultados describen sencillamente lo ocurrido. Al analizar los efectos sobre una variable independiente referida a los hechos ocurridos desde la adjudicación, la incidencia de las terceras variables resulta sin duda mucho mayor. Por lo tanto, resulta más comprometido intentar alcanzar conclusiones definitivas que no incorporen todos los matices oportunos.

El tiempo necesario para completar la urbanización está condicionado por otros aspectos, independientes de la mayor exigencia que pueda ejercerse a través de un concurso sobre los agentes, una vez que han obtenido la condición de urbanizador. Como posibles factores incidentes en los plazos de ejecución apuntaremos hacia las disconformidades en la documentación presentada por el adjudicatario del Programa (ya fuese por escasa diligencia o por falta de interés en dinamizar el proceso una vez obtenida la condición de agente urbanizador); el tamaño de las actuaciones, influyendo en los plazos de tramitación en la medida en que se incrementa el número de propietarios (debido a la gran división de la estructura de la propiedad en la Comunidad Valenciana) con las dificultades intrínsecas que conllevan estas actuaciones; o la situación del planeamiento en el momento de la aprobación del Programa, con la incidencia que tendrían en los plazos las posibles modificaciones de la ordenación estructural.

3.2.d Interpretación sobre la escasa incidencia de la competencia explícita en los resultados de la gestión

Los datos indican que fueron escasas las diferencias entre los resultados de la gestión de actuaciones adjudicadas con competencia explícita y sin ella. Atribuimos este hecho en gran medida a la falta de desarrollo reglamentario de la LRAU. La ausencia de bases reguladoras de los concursos, y de los criterios explícitos de baremación municipal, limitó el alcance de la resolución de los concursos. Esta situación condujo en la experiencia alicantina a que la presentación de propuestas alternativas a la original, una vez convocado el concurso por el proponente de esta última, no incidiera en la adjudicación. Veamos.

a) La competencia entre propuestas de proyecto es escasa, lo que adicionalmente se traduce en una muy reducida competencia por la gestión.

De las 45 actuaciones tramitadas con gestión indirecta, fueron 37 las alternativas técnicas originales aprobadas. O sea, en el $82 \%$ de los casos, la alternativa técnica que sirvió para abrir el procedimiento fue la que resultó finalmente aprobada. Además, en la misma proporción de los casos la titularidad de la plica elegida para la gestión ( $P$ J-E) coincide con la de quien inició el procedimiento de concurso en cada actuación, es decir, la que abría la fase de información pública (datos no mostrados). En otras palabras, el primer agente en presentar un PAI para urbanizar una unidad de ejecución bajo el sistema de gestión indirecta, suele ser el que finalmente recibe su adjudicación, convirtiéndose en el urbanizador de la actuación. 
b) La competencia real entre las propuestas de gestión es muy escasa o nula.

En general la competencia, de producirse, ha sido entre alternativas técnicas, o sea, entre propuestas de planeamiento y/o anteproyectos de urbanización. Sin embargo, fueron escasas las adjudicaciones donde las proposiciones para la gestión entraron en competencia directa o real, ya que optaban por adjudicar opciones técnicas distintas. El estudio realizado prueba que únicamente en un $11 \%$ de los casos llegó a existir competencia explícita para la ejecución de una determinada alternativa técnica.

Ahora bien, la clave que permite explicar estos resultados es que en todas las actuaciones, el agente que presentó la alternativa técnica aprobada fue quien obtuvo la condición de urbanizador (datos no mostrados). Por lo tanto podríamos concluir que, con la configuración de las reglas del juego de la LRAU, la competencia, de existir, se produce entre opciones de proyecto pero difícilmente podría competirse por la gestión. Evidentemente, la primera explicación a este hecho reside en que, en buena lógica, el autor de la alternativa técnica es su mejor conocedor y quien más puede afinar en la estimación de los costes de obra, factor clave en la composición de las cargas de urbanización. No obstante, ello no debería excluir la posibilidad de que el sistema permitiese la deseable formulación de plicas sólidas que, con las condiciones adecuadas, pudieran mejorar las condiciones de la gestión de la propuesta original.

\section{Conclusiones experimentales}

\section{del planeamiento}

4.1 La competencia latente introducida con la LRAU facilitó la ejecución efectiva La experiencia indica que, con la aplicación del modelo valenciano de gestión, se dinamiza la ejecución de los ámbitos definidos por el Plan General de Alicante. La ruptura del monopolio de la gestión genera un impulso para la participación de los agentes profesionales (entendidos como aquellos cuya actividad principal consiste en la construcción, en la promoción inmobiliaria o en la financiación la misma) y provoca un estímulo para la intervención de los propietarios originales de suelo, que se profesionalizan en respuesta al estímulo de la competencia latente. En cualquier caso, el objetivo de los agentes participantes es conseguir un mayor control sobre las condiciones de ejecución del planeamiento, a fin de limitar su esfuerzo financiero.

\subsection{Escasa competencia explícita}

Las actuaciones cuya adjudicación se produjo entre propuestas en competencia, se reducen a un $36,6 \%$ de los casos. La competencia efectiva, donde diversos agentes licitaron por la alternativa técnica aprobada, existió sólo en un $11 \%$ de las unidades de ejecución.

Nuestras interpretaciones sobre la escasez de competencia explícita se dirigen en dos líneas:

a) El margen legal máximo de 40 días para la presentación de propuestas alternativas a la original resultó demasiado estrecho para que la concurrencia actuase de forma efectiva.

b) Los proponentes sólo intervinieron en la medida en que mantenían posiciones avanzadas en la propiedad del suelo. O sea, en la mayoría de los casos, los sujetos que se movilizaron para formular propuestas eran propietarios de terrenos incluidos en las respectivas actuaciones (las únicas) que pretendían urbanizar. Al analizar su comportamiento en los concursos de adjudicación de Programas observamos que participaron muchos agentes diversos, interviniendo escasas veces. Podríamos resumir lo ocurrido mediante un símil deportivo según 
el cual, la ejecución del planeamiento alicantino se encomendó a dos grupos o ligas de competidores: la primera, donde participan pocos agentes gestionando mucho techo, y la segunda, en la que intervienen muchos agentes con poco suelo.

A falta de poder confirmar esta conclusión a través del conocimiento de la estructura de la propiedad en el momento de la convocatoria del concurso, extraemos de los datos un hecho, cuanto menos, singular. Al centrarnos en las actuaciones de mayor tamaño constatamos que no hubo, entre las empresas participantes en los concursos, ninguna cuyo ámbito de actividad no estuviese centrado específicamente en la comarca de l'Alacantí. Esto reafirma la especial cercanía a la propiedad que requieren los operadores privados participantes en la producción de ciudad, a diferencia de otras cadenas productivas donde la obtención de las materias primas se realiza en mercados transparentes y uniformes.

Por tanto, el hecho fundamental es que, como consecuencia de las condiciones de la legislación estatal en el régimen del suelo, tanto para los agentes profesionales pretendiendo acceder a la propiedad por la vía urbanizadora, como para los terratenientes forzados a convertirse en urbanizadores, el verdadero negocio sigue estando en la tenencia de suelo (FERNÁNDEZ, 2005).

4.3. Se produjeron escasas diferencias entre los resultados de la gestión entre actuaciones adjudicadas con competencia explícita y sin ella.

La existencia de competencia explícita no se tradujo en una clara mejora de la gestión del planeamiento. Tan sólo se produjo una minoración de las cargas urbanísticas referidas al beneficio del urbanizador y los gastos de gestión.

Al buscar las posibles causas de esta escasa diferencia entre los resultados de la gestión entre actuaciones con o sin competencia explícita, deberíamos, más allá de las circunstancias ajenas o terceras variables (tendencias de mercado, distribución de la propiedad, régimen del suelo en la legislación estatal) que acompañan a nuestro análisis, centrarnos en la interpretación de las condiciones intrínsecas del sistema.

a) No se pudo explotar todo el potencial del modelo valenciano en lo relativo a la gestión debido a la falta de desarrollo reglamentario de la Ley. Además, tampoco se exploraron las posibilidades generadas por el artículo 45.2 "b" de la LRAU ${ }^{3}$. Todo ello supuso una ausencia de bases municipales reguladoras de los concursos que, con carácter previo, hubieran servido de orientación para la formulación de las propuestas de programación. Esta situación se hace evidente ante la inexistencia de propuestas que introdujeran un compromiso de reserva de terrenos destinados a vivienda protegida.

\footnotetext{
${ }^{3}$ Artículo 45 LRAU: Iniciación del procedimiento a iniciativa de un particular.

1. Toda persona, sea o no propietaria del terreno, puede solicitar del Alcalde que someta a información pública una alternativa técnica de Programa comprensiva de los documentos expresados en los apartados A) y B) del artículo 32 y, en su caso, acompañada de una propuesta de planeamiento o/y de Proyecto de Urbanización.

2. El Alcalde podrá:

A) Proponer al Ayuntamiento-Pleno que desestime la petición. El Pleno podrá desestimarla razonadamente o establecer unas bases orientativas para la selección del Urbanizador, acordando lo dispuesto en el siguiente apartado.

B) Someterla a información pública, junto a las observaciones o alternativas que, en su caso, estime convenientes.
} 
b) Las condiciones del concurso donde, en un solo acto plenario, se llegaba a la aprobación de la alternativa técnica y a la selección de la proposición jurídico-económica, limitaron la posibilidad de obtener mejoras entre las candidaturas dado que los aspirantes a urbanizador desconocían, en el momento de redactar sus plicas, el objeto por el que licitaban (la alternativa técnica que sería finalmente aprobada). Este aspecto provocó que la competencia entre propuestas de proyecto fuese escasa y que, en la práctica, la competencia real o efectiva entre las propuestas de gestión fuese prácticamente inexistente.

\section{valenciano.}

5. La nueva Ley Urbanística Valenciana. Escenarios de futuro para el modelo

La experiencia aplicativa de la LRAU puso en evidencia la insuficiente regulación de determinados aspectos procedimentales, lo que hacía necesarias algunas mejoras en el sistema concursal. Esencialmente, los ajustes debían ir dirigidos a perfeccionar el establecimiento de plazos y de los procesos informativos. También debían ofrecer una respuesta adecuada ante situaciones de cierta indefensión sobre pequeños propietarios. Tras diez años de vigencia, la LRAU fue derogada con la aprobación de la Ley 16/2005, de 30 de diciembre, Urbanística Valenciana (LUV) que, en lo que a la gestión urbanística se refiere, mantiene los aspectos fundamentales del denominado modelo valenciano para la gestión urbanística.

Más allá de la necesidad de ajustes en la regulación del sistema, la tramitación de la nueva ley se vio envuelta en una fuerte polémica surgida a raíz de un requerimiento de la Comisión Europea de Mercado Interior (marzo-diciembre 2005) que interpretaba que la adjudicación de la urbanización debía ser regulada siguiendo el sistema de contratación de obra pública (Directiva 93/37/CEE). Esta cuestión, que fue sometida a interesantes debates desde la puesta en marcha de la renovación legal, ya había reunido respuestas con un alto grado de consenso doctrinal $^{4}$, en la dirección opuesta a la de considerar al urbanizador como un contratista de obra pública. La situación creada a partir del requerimiento europeo no deja de suponer una paradoja puesto que, de imponerse esta versión, debería ponerse en entredicho todo el sistema urbanístico español que delega en la propiedad del suelo la facultad pública de urbanizar, a través del famoso y singular principio de equidistribución de beneficios y cargas.

En cualquier caso, el modelo valenciano para la ejecución del urbanismo encuentra continuidad con la LUV, convertida en un nuevo híbrido legal que funde la ley de contratos con el sistema urbanístico español. Ello se traduce en un cambio de las reglas de concurso:

- Desaparece la posibilidad de plicas cruzadas licitando por una misma solución técnica. Con la LUV las propuestas programáticas consisten en un paquete cerrado que liga indisolublemente la alternativa técnica y la proposición jurídico-económica. Por tanto la elección de un Programa supone la aprobación conjunta del proyecto y de las condiciones para su gestión.

- Se establecen bases reguladoras de la gestión indirecta.

- Se distingue entre las figuras del agente urbanizador y del constructor, que se someten a concursos por separado.

\footnotetext{
${ }^{4}$ Véase, a modo de muestra, el número monográfico de la revista Documentación Administrativa, $n^{\circ}$ 261-262, septiembre 2001 - abril 2002, INAP, Madrid.
} 
- El procedimiento de concurso adquiere mayor complejidad, sobre todo en lo que respecta al cómputo de los plazos y a los requisitos de aviso a los titulares catastrales.

- Se elimina el procedimiento simplificado de la LRAU, al corresponder la convocatoria del concurso única y exclusivamente al Pleno municipal.

Dadas la cercanía en el tiempo desde la entrada en vigor de la LUV y la reciente aprobación del Reglamento de Gestión Urbanística y Territorial (Decreto 67/2006, de 12 de mayo) que la desarrolla, resulta prematuro evaluar ahora el efecto de la reforma. No obstante, desde la misma tramitación de la LUV se han percibido signos de inquietud en los sectores profesionales afectados a raíz de la complejidad del nuevo procedimiento de concurso. Esta reacción supone que las nuevas reglas provocarán, en primer término, una dilatación de los plazos de tramitación y el subsiguiente sobrecoste. En cualquier caso, con el paso del tiempo será la experiencia la que determine el grado de validez de las reformas emprendidas.

\section{Escenarios de futuro}

Más allá de los resultados de la gestión analizados en este trabajo, las valoraciones sobre la experiencia aplicativa de la LRAU han quedado absorbidas por un debate, todavía abierto, donde la condición compleja del urbanismo sale a relucir con toda su fuerza. A menudo consiste en una confrontación entre postulados teóricos o en justificadas apreciaciones derivadas de la experiencia práctica. Otras veces, sin embargo, las críticas surgen simplemente como una expresión sesgada de intereses parciales. En cualquier caso, entendemos que antes de realizar cualquier valoración global sobre los efectos derivados de la aplicación de un determinado instrumento legal, sería oportuno referir los resultados al singular marco socioeconómico y cultural en el que se desarrolla. Esto permitiría reconocer la existencia de fenómenos similares a los que son objeto de crítica en otros contextos geográficos, no siendo atribuibles simplemente a la aplicación de una u otra determinada norma.

Dicho esto, es evidente que la eficacia en la gestión ha supuesto la aparición en la superficie urbana de todas las carencias (y también las bondades) del planeamiento que se llevó a ejecutar. En nuestra opinión, el avance en el conocimiento sobre los sistemas de planificación y de producción urbana requiere extraer del debate sobre el urbanismo, y de la confusión que lo rodea, aquellos instrumentos o prácticas cuya eficacia ha sido contrastada y avalada por la experiencia. En este sentido, la liberalización de la gestión urbanística debiera formar parte de las cuestiones asumidas, aún siendo mejorables las normas que la regulan. De momento, fijemos algunos aspectos generales a desarrollar en la voluntad de avance del modelo concurrencial.

La experiencia práctica del modelo valenciano ha generado una incidencia notoria sobre la urbanización. Con ello sólo se aplicó la liberalización a una parte del proceso de ejecución del planeamiento, quedando la fase edificatoria todavía al margen de la libre competencia. He aquí una de las vías principales abiertas por los postulados teóricos que quedan aún por explorar. La extensión del sistema concursal a la ejecución de la edificación supondría una dinamización de las operaciones de intervención en la ciudad interior, con las consiguientes mejoras en los barrios consolidados. Esta posibilidad, introducida por la LRAU a través de las figuras de los agentes edificador y rehabilitador, no fue desarrollada en la práctica. 
También debería consolidarse un pronunciamiento explícito de la voluntad pública de ciudad, mediante la redacción de oficio del planeamiento y a través de los mecanismos reguladores de los procesos ejecutivos. La definición de antemano del producto urbano deseado facilitaría la gestión y ejecución del mismo, permitiendo establecer en el momento oportuno el grado de participación pública en las plusvalías generadas por el plan.

Finalmente, sería factible un incremento de las garantías a los particulares involucrados en los procesos de creación o de transformación urbana, y por extensión de las garantías a la ciudadanía, con sólo publicitar de forma accesible no sólo los planes sino también sus avances de intenciones. Bastaría la actualización de estos contenidos en un medio público como Internet para elevar el grado de consenso que las decisiones de intervención en el medio físico requieren.

Por último, con el propósito de actualizar los retos de la gestión del urbanismo convendrá recordar lo propuesto en 1993 por el urbanista que con su lucidez contribuyó a reunir las ideas motrices del sistema concurrencial, materializadas en parte en su modalidad valenciana.

"Hay que abrir a la libre concurrencia empresarial la facultad de edificar y que no sea más un monopolio con todas sus ventajas para el propietario del suelo. Hay que hacer transparentes los precios del suelo y la vivienda sometiéndolos al mercado real de oferta/demanda, discriminando claramente el precio real del uno del precio derivado de los usos urbanísticos creados por la colectividad en el otro. Hay que dar a la propiedad del suelo lo que es del suelo y devolver a la sociedad lo que es de la sociedad." [Javier García-Bellido (1994): "Configuración de la 'propiedad desagregada': Dualidad de derechos en la propiedad inmobiliaria», parte II, Revista de Derecho Urbanístico, $\mathrm{n}^{\circ}$ $138,547-634]$

Todavía queda, por tanto, bastante camino por recorrer.

\section{BIBLIOGRAFÍA}

Blanc, F. (1997): "Los efectos de la LRAU sobre la actividad urbanizadora: causas y consecuencias de una transformación", Ciudad y Territorio. Estudios Territoriales, XXIX (112), Ministerio de Fomento, Madrid.

FERNÁNDEZ, G.R. (1993): "Necesidad y oportunidad de una visión alternativa al tratamiento legal del proceso urbanístico", Ciudad y Territorio. Estudios Territoriales, nº 95-96, Ministerio de Fomento, Madrid.

- (2000): "La reforma de la legislación del suelo. El caso de la Comunidad Valenciana", Geometría, $\mathrm{n}^{\circ}$ 27-28, Colegio Territorial de Arquitectos, Almería.

- (2005): "Mitos y realidades del agente urbanizador", Ciudad y Territorio. Estudios Territoriales, $\mathrm{n}^{\circ} 143$, Ministerio de Vivienda, Madrid.

- (2005): "Derecho a especular", diario El País, sección de Economía, edición de 30 de junio.

FERnÁNDEZ, G.R.; MARín, B. y FERnÁNDEZ, P. (2003): Guía básica para el análisis de la viabilidad económica de actuaciones inmobiliarias, ICARO, Colegio Territorial de Arquitectos, Valencia. 
GAJA, F. (2000): "La producción de suelo urbanizado como objetivo de la ordenación urbanística", Urban, 5, Departamento de Urbanística y Ordenación del Territorio, Universidad Politécnica de Madrid.

GARCIAA-BELLIDO, J. (1993): "La liberalización efectiva del mercado del suelo. Escisión del viejo derecho de propiedad inmobiliaria en una sociedad avanzada", Ciudad y Territorio. Estudios Territoriales, $\mathrm{n}^{\circ}$ 95-96, Ministerio de Fomento, Madrid.

- (1994): "Configuración de la "propiedad desagregada": Dualidad de derechos en la propiedad inmobiliaria», partes I y II, Revista de Derecho Urbanístico, n 138 y 139.

- (1999): "La excepcional estructura del urbanismo español en el contexto europeo", Documentación Administrativa, 252-253.

MERLO, J.L. \& RIBES, J. (2002): Guía básica para la redacción de programas para el desarrollo de actuaciones urbanísticas. ICARO, Colegio Territorial de Arquitectos, Valencia.

MIGUEL, J.L. (1997): "La iniciativa privada y la LRAU", Ciudad y Territorio. Estudios Territoriales, XXIX. Ministerio de Fomento, Madrid.

ModRego, F. (1997): "La liberalización del urbanismo. La experiencia valenciana", Ciudad y Territorio. Estudios Territoriales, XXIX (112), Ministerio de Fomento, Madrid.

ModREGO, F. (2000): "Cuarenta meses de aplicación de la LRAU de la Comunidad Valenciana", Ciudad y Territorio. Estudios Territoriales, XXXII (123), Ministerio de Fomento, Madrid, 111133.

MoliNí, F. (2004): "La competencia durante el planeamiento: teoría y aplicación a escala municipial", Ciudad y Territorio. Estudios Territoriales, XXXVI (139), Ministerio de Fomento, Madrid.

MuÑoz GieLEN, D. (2005): Possibilities to use legally binding land use rules in a strategic way, OTB Research Institute for Housing, Urban and Mobility Studies, TU Delft, Países Bajos. Ponencia presentada en el Congreso AESOP, Viena.

- con KHORTAS ALTES, W.K. (2006): "Lessons from Valencia: Separating Infrastructure Provision from Land Ownership", Town Planning Review, en proceso de revisión.

PAREJO, L. \& BlANC, F. (1999): Derecho urbanístico valenciano, Tirant Lo Blanch, Valencia.

PAREJO, L. (2002): "La cuestión de la constitucionalidad de la figura urbanística del "Urbanizador" en su concreta versión, la de la legislación valenciana", Documentación Administrativa, $\mathrm{n}^{\circ}$ 261-262, INAP, Madrid, 69-108.

VAQUER, M. (2002): "La fuente convencional, pero no contractual, de la relación jurídica entre el agente urbanizador y la Administración urbanística.", Documentación Administrativa, $\mathrm{n}^{\circ}$ 261-262, INAP, Madrid, 231-256.

\section{Agradecimientos}

El autor agradece los comentarios de Gerardo Roger Fernández, Alejandro Escribano, Josep Roca, Sara Mur y, muy especialmente, de Demetrio Muñoz por sus sugerencias en el texto.

Este trabajo es resultado de la colaboración de los Servicios de Planeamiento y Gestión de la Gerencia Municipal de Urbanismo del Ayuntamiento de Alicante. El autor agradece todo el apoyo recibido de los empleados municipales en la extracción y en la interpretación de los datos.

Por último, el autor expresa su más profundo agradecimiento a Javier García-Bellido por su entusiasmo, su apoyo y su inspiración en la investigación que sirvió de base para este artículo. Sus enseñanzas siguen siendo motivo de inspiración. 